\title{
A Atuação Política dos Estados Unidos no Cenário Internacional: notas
}

\section{introdutórias}

The political action of the United States on the international scene: introductory notes

Marcelo Rodrigues Lemos ${ }^{1}$

\section{RESUMO}

Este artigo mostra como os Estados Unidos desenvolvem sua centralidade internacional desde o fim da Segunda Guerra Mundial, em 1945, até os dias atuais. Para o cumprimento desta proposta, uma pesquisa bibliográfica foi realizada, retomando obras importantes sobre este debate. A verificação da posição de destaque ocupada pelo país revelou que a hegemonia americana é garantida por instrumentos complexos e oscilantes.

Palavras-chave: Estados Unidos; Hegemonia; Política.

\begin{abstract}
This article shows how the United States develop its international centrality since the end of World War II in 1945 to the present day. To accomplish this proposal, a theoretical research was conducted by analyzing important works on this debate. The verification of the prominent position occupied by the country revealed that American hegemony is guaranteed by complex and oscillating instruments.
\end{abstract}

Keywords: Hegemony; Policy; United States.

\section{INTRODUÇÂO}

A análise da complexa condição de excepcionalidade dos Estados Unidos no cenário internacional é o objeto deste texto, tendo em vista que este tema desperta o interesse de muitos estudos (JOHNSON, 2007; KIERNAN, 2009; MEAD, 2006; NYE JR., 2002; PECEQUILO, 2001, 2005, 2012; PECEQUILO, RESENDE, DINIZ, 2010; SANTOS, 2007; TODD, 2003, TOTA, 2000). A verificação da posição de destaque ocupada pelo país

\footnotetext{
${ }^{1}$ Doutorando em Ciências Sociais, UNESP/Marília, Bolsista CAPES, Marília, Brasil. 
requer a revisão de princípios ligados às estratégias de sua política externa e dos recursos que possibilitam a construção da hegemonia norte-americana no contexto global.

O Estado Americano dissemina globalmente seu modo de vida e, por mecanismos ideológicos de atração cultural, indivíduos do mundo todo se debruçam para contemplar suas grandezas. Vale ressaltar, entretanto, que os Estados Unidos não suscitam apenas a cobiça dos estrangeiros, mas também o ódio por parte de muitos grupos sociais mais radicais e fundamentalistas. (NYE JR., 2002, p.14).

Assim, o objetivo deste artigo é mostrar como os Estados Unidos desenvolvem sua centralidade internacional desde o fim da Segunda Guerra Mundial, em 1945, até os dias atuais. Ao longo deste tempo, a primazia norte-americana é garantida por complexos instrumentos geopolíticos, os quis são habilidosamente manipulados para a manutenção da nação como a maior potência do mundo.

Por se tratar de uma análise essencialmente qualitativa, a metodologia utilizada para a confecção do texto baseou-se nos referenciais técnicos da pesquisa bibliográfica. Esta, por sua vez, permite o levantamento dos principais estudos já realizados sobre o tema escolhido, além da posterior seleção daqueles que servirão diretamente à redação do novo artigo. Logo, o mapeamento da literatura pertinente é um procedimento metodológico eficaz para pesquisador em seu trabalho acadêmico, pois o auxilia na delimitação das referências usadas na construção da reflexão pretendida. (SEVERINO, 2007).

\section{A excepcionalidade americana: apontamentos iniciais}

Consultando as publicações relacionadas a este debate, constatou-se que a atuação dos Estados Unidos no cenário geopolítico global está dividida entre grupos que defendem duas posições polares, os isolacionistas e os internacionalistas. Os primeiros, já praticamente ausentes na contemporaneidade, balizados por uma política de não engajamento, rejeitam determinadas alianças e acordos com outros Estados, valorizando interesses essencialmente nacionais. (NYE JR., 2002).

Já os segundos se subdividem entre unilateralistas e multilateralistas. Os unilateralistas creem que os Estados Unidos, em função de sua proeminência militar, não devem ser dóceis com o resto do mundo e podem perseguir com toda ênfase os seus 
interesses. Em contraponto, os multilateralistas acreditam que o país possui um importante papel na estabilidade global, mas precisam utilizar meios alternativos de poder, visto que o poder militar não é suficiente para a condução de muitos assuntos de interesse nacional e internacional.

0 único consenso entre os grupos que divergem quanto à gestão da política externa americana é o de que o país é hegemônico e deve permanecer como tal. Assim, o rótulo de superpotência, delegado aos Estados Unidos desde a queda da União Soviética, prende-se a elementos de toda ordem, desde o uso do dólar como moeda reguladora das trocas comerciais internacionais, passando pelo poderio militar inquestionável, ao idioma considerado obrigatório e os produtos massificados da cultura americana que são distribuídos mundo afora. (NYE JR., 2002, p.25).

Além disso, a capacidade de conquistar os resultados desejados e a possibilidade de alterar o comportamento de outros países na busca desses próprios resultados revela o poder dos Estados Unidos na configuração da geopolítica internacional. Como se sabe, o poder de um país está comumente vinculado à posse de determinados recursos que o potencializam, como extensão territorial, contingente populacional, questões ambientais, força econômica, vigor bélico, solidez política e governamental. Mas, para que a potencialidade dos recursos de poder americanos se efetivasse e se materializasse em benefícios para a nação, foi fundamental a elaboração de ações políticas guiadas por lideranças capacitadas. (NYE JR., 2002, p.31).

Ao longo do tempo, esses recursos de poder vão se modificando e, em fases particulares, cada um deles adquire maior ou menor potencial decisório na gestão política interna e externa das nações. Em épocas de guerra é a capacidade bélica que entra com peso decisivo nos conflitos. Uma grande população também pode ajudar como alternativa de poder ao elevar as economias nacionais com o provimento de impostos. Já o progresso tecnológico e industrial colabora na construção da infraestrutura logística necessária à boa gestão dos países. No caso dos Estados Unidos, seu poder é legitimado pelo somatório de todos esses recursos. (NYE JR., 2002).

Atualmente, as bases do poder estão se distanciando da capacidade militar e da tomada de territórios por quatro motivos centrais. 0 primeiro diz respeito ao potencial devastador das armas nucleares que se revelam um fardo não só para os que podem ser destruídos por elas, como também para os que delas fizerem uso. Outro fator está ligado Conjuntura Global, vol. 5 n. 1, jan./abr., 2016, p. 115-130. 
à emergência do nacionalismo, o qual cresceu muito forte nas nações antes conquistadas e colonizadas e que agora lutam e resistem com maior firmeza nas invasões estrangeiras. Uma terceira razão está na busca das grandes potências pelo bem-estar de suas populações em detrimento de glórias militares, assim, as perdas humanas nos confrontos são vistas, cada vez mais, de modo bastante negativo e o apoio popular para tais embates só chega com forte justificativa moral. Por fim,

[...] o emprego da força põe em perigo as metas econômicas da maioria das grandes potências atuais. Mesmo os países não democráticos, menos sujeitos à coerção moral popular no que se refere ao uso da força, são obrigados a levar em conta seu efeito sobre os objetivos econômicos que seguem. (NYE JR., 2002 p.33).

Contudo, seria precipitado concluir que o aparato militar não mais influi na atual geopolítica do mundo. Guerras civis continuam eclodindo em razão de vácuos de poder deixados pelo fim de governos centralizadores. Além disso, o receio da ascensão de novas potências pode também configurar motivos para despertar a atenção militar de outras potências maiores. Outra concessão ao uso das forças bélicas é a aparente tranquilidade que elas podem representar em regiões historicamente tensas, permitindo o uso mais seguro de recursos como o petróleo.

Nas últimas décadas, a revolução da informação tem aproximado as fronteiras do globo e o processo de globalização passa a gerar redes e interdependência entre os países, rompendo com distâncias históricas. ${ }^{2}$ Nesse contexto, o poder econômico torna-se essencial, diminuindo parcialmente a relevância do poder militar. Com a globalização da economia, o mercado passa a ser conduzido por forças que nenhum país consegue dominar sozinho, em função de acordos variados de trocas comerciais.

\footnotetext{
2 Vale ressaltar que esta ideia positiva da globalização, enquanto um fenômeno que aproxima e traz benefícios indistintamente a todas as nações, não é consensual. Algumas vertentes, como a do geógrafo brasileiro Milton Santos (2010), expõem o potencial negativo da globalização, ao passo que ela, em muitos casos, também gera a acentuação das desigualdades sociais e econômicas. Em um mundo dividido entre países de centro e de periferia, para os periféricos concorrerem no cenário globalizado é muito complicado, vez que carregam consigo desvantagens históricas. Além disso, as práticas econômicas da globalização sinalizariam não a integração e a interdependência das nações, mas a aproximação dos países centrais com o objetivo da maior exploração dos periféricos.

Conjuntura Global, vol. 5 n. 1, jan./abr., 2016, p. 115-130. 


\section{Formas brutas e brandas de exercício do poder americano}

Para Nye Jr. (2002 p.36), ameaças militares ou embargos e sanções econômicas representam formas de um poder bruto, capaz de induzir os países a certos posicionamentos mediante o receio de restrições ou a perda de parcerias já consolidadas. No caso dos Estados Unidos, para manterem sua força de influência no mundo, a nação também se apoia em um poder brando, que fascina ao invés de coagir. "Neste sentido, é igualmente tão importante estabelecer a agenda na política mundial e atrair os outros quanto forçá-los a mudar mediante a ameaça ou o uso das armas militares ou econômicas."

De modo geral, o poder brando pode representar uma boa alternativa estratégica por sua capacidade de atração e sedução, ao apresentar valores de prosperidade e liberdade de determinado país que muitos outros gostariam de seguir.

No tipo brando de poder as preferências das outras nações passam a ser permeadas pela cultura, pelas ideologias e instituições do país referência. Assim, no uso deste tipo de poder os Estados Unidos passam a inspirar os anseios do resto do mundo com sua democracia consolidada, com a liberdade pessoal e a ideia de ascensão social, tão bem apresentadas em suas produções midiáticas e cinematográficas. Portanto, "0 país que consegue legitimar seu poder aos olhos dos demais encontra menor resistência para obter o que deseja. Contando ele com uma cultura e uma ideologia atraentes, os outros se mostram mais dispostos a acompanhá-lo." (NYE JR., 2002, p.39).

Vale lembrar que as estratégias norte-americanas de preservação da hegemonia são oscilantes entre o emprego do poder bruto e brando, o que não implica no abandono do uso conjunto dos dois, ao passo que eles são reforçados mutuamente. Logo, coerção e atração passam a pautar o comportamento dos países para a realização dos objetivos americanos.

Outro ponto importante neste debate é a capacidade de reação de outras nações perante o domínio americano. 0 assunto pode ser formulado em uma questão: o mundo é complacente com a hegemonia dos Estados Unidos e seu destacado poder ou um equilíbrio de forças passa a ser buscado a fim de que o país não se isole plenamente na liderança global? A resposta para esta pergunta não é consensual, mas, de modo geral, como atesta Nye Jr. (2002, p.45), 
[...] independentemente de como se mede o poder, uma distribuição igual entre os Estados mais importantes tem sido relativamente rara na história, e os esforços para manter o equilíbrio muitas vezes levaram à paz e à estabilidade porque não tinha sentido declarar guerra a uma potência dominante.

Portanto, algo que faz a hegemonia dos Estados Unidos perdurar é o receio de seus desafiantes em provocar sua hostilidade e o vínculo com os aliados que permanecem clamando por sua proteção.

Assim, na concepção de Nye Jr. (2002 p.48), garantir a longevidade do poder americano requer a adoção de formas multilaterais de se fazer política. A definição das preocupações nacionais e internas passa pela inclusão dos interesses globais. Ou seja, o país não pode adotar uma diplomacia unilateral pautada na arrogância de sua supremacia, caso isso ocorra a "[...] preponderância não conseguirá impedir que outros Estados e agentes não estatais empreendam ações para complicar os [...] cálculos [americanos] e [...] restringir [sua] liberdade de ação."

Atualmente, a questão do equilíbrio do poder e a supremacia do poder norteamericano estão relacionadas não apenas às já mencionadas disparidades bélicas ou econômicas ou com a atração exercida pelo poder brando. É preciso, portanto, focalizar os impactos da revolução da informação nos recursos de poder na contemporaneidade, pois "Sob a influência da revolução da informação e da globalização, a política mundial está mudando de maneira que os norte-americanos já não podem atingir todas as metas internacionais atuando sozinhos." (NYE JR., 2002, p.82).

Proporcionando forte descentralização administrativa e disseminando os polos de poder entre agentes não estatais, a revolução da informação traz novas roupagens à diplomacia internacional. Atentos ao fluxo ágil e de menor custo das informações pela internet, os governos agora já não controlam plenamente o que é divulgado e nem o impacto que determinada notícia pode gerar na teia da política global.

“A atual revolução da informação baseia-se nos rápidos avanços tecnológicos do computador, das comunicações e do software que, por sua vez, conduziram a extraordinárias reduções no custo do processamento e da transmissão da informação." (NYE JR., 2002, p.84). Com isso, as redes de informação mudaram mais rápido que os governos, que viram suas atividades se difundirem para outros meios, como o setor 
privado dos conglomerados empresariais ou as instâncias de poder não governamentais do chamado Terceiro Setor.

"Uma consequência política do fluxo cada vez maior de informação pelo novo meio já está clara: os governos perdem uma parte do controle tradicional sobre a informação acerca de suas próprias sociedades." (NYE JR., 2002, p.95). Este fato anuncia mudanças nas tradicionais atividades políticas coletivas, as quais vão se distanciando dos governos centrais, mediante a transferência do poder dos agentes estatais para agentes particulares.

\begin{abstract}
Isto significa que a política externa não será campo exclusivo dos governos [...], tanto os indivíduos como as organizações particulares terão a possibilidade de participar diretamente da política mundial. A disseminação da informação levará a uma distribuição mais ampla do poder, e as redes informais [...] destruirão o monopólio da burocracia tradicional. A velocidade do tempo da internet significa que todos os governos [...] terão menos controle sobre suas agendas. Os líderes políticos desfrutarão de menor grau de liberdade ao reagir aos fatos e terão de dividir o palco com outros atores. (NYE JR., 2002, p.101).
\end{abstract}

Como se vê, os efeitos da revolução da informação na política externa são reais e irreversíveis. 0 modo como os Estados passarão a administrar tais consequências é que permanece turvo. No caso dos Estados Unidos, a ênfase no poder brando indica uma alternativa interessante para a era da informação global. 0 país possui vantagens neste contexto, ao dominarem tecnologias sofisticadas que lhes trazem credibilidade no desempenho internacional. Além disso, com canais de comunicação de ponta, os norteamericanos podem espalhar suas ideias dominantes e seus valores culturais vão, cada vez mais, se tornando referências centrais para o mundo.

Portanto, os meios tradicionais de exercício da hegemonia norte-americana, vinculados ao poder bruto de seu potencial militar e econômico, já não podem negligenciar novas formas de poder brando na era da informação. A política externa dos Estados Unidos precisa trilhar caminhos para além dos convencionais, modificando o modo como opera sua hegemonia global, visto que "Os artífices da política terão de dar mais atenção à questão da credibilidade e à importância do poder brando. E serão obrigados a atuar num palco lotado de agentes não governamentais e indivíduos recentemente investidos de poder." (NYE JR., 2002, p.133). 


\section{O sistema político norte-americano: relações internas e externas}

Como apresentado até aqui, a influência norte-americana no mundo está associada a processos históricos complexos, que envolvem dimensões políticas, econômicas, militares e culturais. As bases da hegemonia americana são especiais por comungarem a força e o convencimento. Por isso, o anseio de preservação desta hegemonia esbarra em estratégias variadas que acabam por dividir a nação.

A polarização entre o engajamento externo e o distanciamento do restante do mundo fez e faz parte da história dos Estados Unidos. Contudo, a vontade da liderança fomenta nos americanos o uso de um instrumental especial, ligado às relações internacionais, que garante sua destacada autoridade. Logo, a soma de elementos estruturais, institucionais e ideológicos legitima o domínio dos Estados Unidos. (NYE JR., 2002; PECEQUILO, 2012).

Para a definição do papel do Estado nas relações internas e externas, o sistema político americano apresenta um sofisticado jogo de forças entre o Congresso e o poder Executivo, jogo este que também é permeável pela participação popular da sociedade civil organizada. (PECEQUILO, 2012, p.11). Neste esquema de forças, conforme destaca Pecequilo (2012, p.11-12),

O predomínio de um ator sobre o outro, ou o estabelecimento de padrões de convivência mais ou menos conflituosos, dependem das circunstâncias, questões e épocas históricas. Por sua vez, a sociedade pode participar diretamente das ações do governo por meio de pressões diretas e indiretas, organizando-se em grupos de interesse, aos quais respondem os representantes eleitos.

O maior ou menor potencial de influenciar as decisões do sistema, por parte de grupos particulares da sociedade, está vinculado a critérios financeiros, ideológicos e de mobilização/organização dos próprios grupos.

Também neste sentido, o governo vai criando limites legais à emergência de novas lideranças, consolidando um sistema político que, embora multipartidário, se vê quase exclusivamente guiado por Democratas e Republicanos. Dessa forma, resta a esses grupos sociais a aproximação com um dos partidos citados. Este fato faz do sistema de governo norte-americano simultaneamente pluralista, do ponto de vista da possibilidade de expressão de opiniões e valores, mas segregacionista, segundo parâmetros econômicos 
e de habilidade da mobilização eficiente dos grupos que acabam se subordinando às tendências majoritárias.

As disputas entre Democratas e Republicanos e dos grupos de interesse que buscam representatividade no regime político acaba por tolher espaços de consenso, impactando no modo como os Estados Unidos estruturam suas táticas externas de atuação, além de obstaculizar decisões sobre a política nacional interna. Assim, é sabido que "Estes debates sobre o papel dos Estados Unidos no mundo e a organização de suas relações internas refletem o contexto atual do país, mas também os valores e tradições históricas nacionais, que correspondem aos fundamentos do sistema norte-americano." (PECEQUILO, 2012, p.12).

Como é de conhecimento geral, após o declínio da União Soviética, os Estados Unidos passaram a ser, de acordo com Pecequilo (2012, p.12) "a única superpotência restante" e este fato trouxe certa angústia aos norte-americanos, que se viram vitoriosos dos embates que combateram o socialismo soviético, mas desgastados ideológica e economicamente pelo conflito bipolarizado que se arrastou por várias décadas.

Nesta época, embora houvesse certeza de sua hegemonia internacional, muitos se questionavam sobre quais seriam as novas atribuições e responsabilidades dos Estados Unidos em um mundo após a Guerra Fria. As linhas alternativas a esta questão se dividiam entre internacionalistas multilateralistas e unilateralistas. "Enquanto a primeira corrente era adotada por democratas e republicanos moderados, a segunda mostrava-se mais presente entre os neoconservadores." (PECEQUILO, 2012, p.13).

Os neoconservadores, que só foram ganhar mais espaço entre os anos de $2001 \mathrm{e}$ 2008 durante o governo de George W. Bush, defendiam, entre outras coisas, a primazia da esfera militar, o intervencionismo internacional visto como missão ativista, a radicalização de preceitos religiosos.

Neste contexto, a escolha por um dos dois modos de internacionalismo era complexa e envolvia visões distintas do exercício hegemônico. Dúvidas quanto ao equilíbrio do poder mundial opunham as perspectivas unipolares e multipolares, se os Estados Unidos deviam se situar reafirmando sua supremacia militar e seu poder duro ou admitindo a desconcentração e pulverização do poder para outros Estados e agentes 
particulares; dúvidas que só apareceram em razão da complexidade cada vez maior do mundo e sua geopolítica.

Do pós-Guerra Fria ao cenário indicado pela contemporaneidade, várias mudanças foram observadas nas relações internacionais. Novas pautas passaram a ser trabalhadas, como o nascimento de outras instâncias institucionais de poder e órgãos de governança, os impactos da globalização com a proeminência das tecnologias da informação, preocupações e dilemas com o meio ambiente e a concepção da sustentabilidade. Mas antigas posições permaneceram sendo mantidas, tal como a manutenção da atuação dos instrumentais democráticos e liberais dos Estados Unidos, em vigor desde 1945. (PECEQUILO, 2005, p.15).

\section{Política externa dos Estados Unidos: pautas contemporâneas de enfrentamento}

Atualmente, circunstâncias positivas e negativas passam a dividir espaço nos sistemas políticos, econômicos, culturais e militares globais. Aspectos positivos como o crescimento da democracia em sociedades mais livres, além da ampliação do acesso às inovações tecnológicas são percebidos. Porém, também é possível identificar conflitos étnicos e religiosos em disputas radicais, o receio das armas de destruição em massa ou o terrorismo, a expansão da devastação do meio ambiente e do tráfico de drogas. (PECEQUILO, 2005, p.16).

Embora os Estados Unidos continuem a exercer sua centralidade no mundo, outras potências também buscam se reposicionar na disputa pelo poder internacional. Com isso, o sistema geopolítico global vai, aos poucos, caminhando "[...] em direção ao estabelecimento de uma nova hierarquia, refletindo a importância de países como Alemanha (ou União Europeia), Japão, Rússia e China.” (PECEQUILO, 2005, p.16).

Logo, "No atual contexto, a habilidade dos Estados de conquistar, manter, expandir e mesclar as formas tradicionais e as renovadas de poder cada vez mais definirá suas possibilidades internacionais e o alcance e efetividade de sua ação externa." (PECEQUILO, 2005, p.16). Ou seja, é fundamental aos Estados Unidos reavaliar suas prioridades no âmbito internacional, revisando os princípios norteadores de suas ações externas, a fim de elaborarem novos paradigmas de intervenção no mundo. 
Para a conservação dos interesses estratégicos dos Estados Unidos o que se vê, atualmente, é a busca da

\begin{abstract}
Preservação da liderança e da estabilidade mundial por meio de uma posição de proeminência, impedindo a emergência de hegemonias regionais e promovendo a expansão dos valores da democracia e do livre mercado com posturas que cultivam elementos liberais e realistas de política externa. Em outros termos, tais diretrizes podem ser encaradas como uma tradução do interesse nacional dos Estados Unidos, visando a garantia do seu lugar no mundo e a preservação de sua segurança. (PECEQUILO, 2005, p.20).
\end{abstract}

É nesta direção que a alternativa do engajamento "seletivo" apareceu, por um tempo, como uma boa opção ao Estado americano, ao sugerir a reorientação das prioridades do país para que o mesmo reduzisse os custos de sua presença estrangeira, reavaliando a extensão de sua própria dominação mundo afora. "Para isso, é preciso que os Estados Unidos limitem suas ações a algumas áreas de interesse, economizando recursos e permitindo que seus parceiros compartilhem tarefas e responsabilidades da administração do sistema." (PECEQUILO, 2001, p.121).

Com o engajamento "seletivo" associado ao multilateralismo, os Estados Unidos passam a conceder espaços e benefícios mais amplos nos acordos e alianças externas, numa clara resposta às críticas da concentração de poder. Tudo isso não significa, entretanto, que eles abdicaram da liderança ou do comando, mas apenas reformularam suas bases hegemônicas ao contexto que sugeria a multipolarização do poder. (PECEQUILO, 2001, p.121).

Mas, como um movimento continuamente pendular, o unilateralismo substituiu novamente o multilateralismo vigente desde 1945, tornando-se novamente uma referência em razão do medo do terrorismo, proporcionado pelos atentados de 11/09/2001, despertando também fortes combates contra o fundamentalismo islâmico.

Porém, o unilateralismo volta a declinar em meados de 2005, quando o governo George W. Bush percebe que seu modelo de desapego à governança global e endurecimento militar estava desagradando americanos e estrangeiros. Com isso, seus acordos que romperam com alianças que permitiam uma imagem positiva da hegemonia voltam a ser renegociados. Esta postura de maior engajamento e de ampliação da diplomacia é percebida ainda hoje no governo de Barack Obama, iniciado em 2009. 
Os prognósticos relativos ao futuro da hegemonia norte-americana são muitos, mas convergem para a ideia de que o país precisa transformar seu poder predominante em uma espécie de consenso internacional, tornando vastamente aceitáveis suas normas e princípios internacionais. Tudo isso pode convencer o resto do mundo da expressividade inevitável da figura dos Estados Unidos nas decisões estrangeiras, sejam elas bastante amplas ou até mesmo regionais. (NYE JR., 2002).

Para adquirirem este consenso externo, o país necessita, antes, lidar com problemas domésticos, mobilizando sua população para o enfrentamento austero de suas crises econômicas que geram incertezas, desemprego e déficits na balança comercial e nas contas do governo; para a ampliação da coesão nacional entre grupos étnicos e religiosos com o abandono de práticas radicais e fundamentalistas; para o fim da intensa polarização social e seu abismo entre ricos e pobres, com melhor distribuição de renda e avanços infraestruturais. (PECEQUILO, 2012).

Além das questões internas, os Estados Unidos precisam, na atualidade, incorporar uma agenda global de problemas, para ter assegurada sua posição estratégica no mundo. (PECEQUILO, 2012, p.151). Esta agenda lida com temas como o meio ambiente, assunto controverso entre os americanos, os quais cobram posturas mais sustentáveis dos demais países, mas contraditoriamente não conseguem efetivá-las em seu próprio território.

O futuro das sociedades e a qualidade de vida de suas populações estão intimamente associados à vontade dos Estados em limitar os impactos nocivos ao meio ambiente. Contudo, as soluções políticas para as demandas ambientais são difíceis em razão de elas serem não só globais, mas nacionais e localizadas. Os efeitos da degradação são sentidos no longo prazo, fato que vai postergando meios de frear a intervenção inapropriada sobre o meio ambiente. Os custos e a burocracia para a correção dos problemas são significativos, desestimulando acordos que cuidem desta agenda.

No caso específico dos Estados Unidos, nota-se uma predileção por soluções muito mais retóricas que propriamente práticas frente ao dilema ambiental, fato que desperta críticas por parte da comunidade internacional. (PECEQUILO, 2012, p.153).

Outro tópico da agenda são os direitos humanos, zelados de modo oscilante pelos Estados Unidos, que ou tratam os assuntos humanitários com elevada prioridade, ou os 
negligenciam a políticas bastante tênues. Além disso, por vezes o país faz reinterpretações convenientes de normas humanitárias internacionais, de acordo como interesses momentâneos específicos.

O fato é que temas como a promoção da democracia, igualdade de gênero, defesa da liberdade religiosa, fim da tortura e tratamento digno de prisioneiros e suspeitos de terrorismo, fechamento de prisões secretas, entre outros, precisam fazer parte da política dos Estados Unidos de modo realmente engajado e convincente. (PECEQUILO, 2012, p.160).

Na pauta internacional entra ainda economia e comércio. Estes temas, embora intimamente presos a fatores internos à organização dos Estados Unidos, ganham significativa importância muito em razão de o dólar americano ser a moeda de reserva internacional, o que eleva ainda mais o poder do país. No entanto, existem circunstâncias que também fragilizam o peso da economia americana no palco nacional e externo, como sua matriz produtiva e social dependentes de um consumo energético acentuado e pouco eficaz e ao alto consumismo que gera o endividamento de muitos setores da população americana.

Além dos já mencionados déficits do setor comercial e público, críticas ao protecionismo e o uso de subsídios especialmente para o setor agrícola são comuns, pois pensam contra o equilíbrio de poder na esfera comercial internacional. A predileção com gastos militares em detrimento de áreas como educação e saúde são outras controversas do regime econômico dos Estados Unidos.

Assim, de acordo com épocas de crise e encolhimento do crescimento econômico ou momentos de vigor e superávit, a situação da economia americana vai se desenhando e os governos vão adotando estratégias para otimizar seus orçamentos.

Ainda sobre a questão específica do comércio, uma tendência de alinhamento dos países em desenvolvimento às orientações dos desenvolvidos tem-se mostrado frequente. Este fato favorece a vida comercial da maior potência econômica do globo, que utiliza meios para cooptar os Estados em acordos claramente vantajosos aos Estados Unidos. Neste sentido, prevalecem acordos comerciais unilaterais e bilaterais entre as nações. (PECEQUILO, 2012, p.164). 
Órgãos, instituições, associações e blocos internacionais para a condução do comércio no mundo, como o Fundo Monetário Internacional - FMI, o Banco Mundial, a Organização Mundial do Comércio - OMC, o G20, os BRICS - Brasil, Rússia, Índia, China e África do Sul passam a delimitar "[...] uma nova arquitetura de poder geoeconômico global" (PECEQUILO, 2012, p.168). Ainda assim, por parte dos norte-americanos, "Mantém-se a prioridade e o foco [...] nas instituições nas quais os Estados Unidos e a União Europeia possuem maior margem de manobra e poder decisório." (PECEQUILO, 2012, p.169). Em linhas gerais,

\begin{abstract}
Prevê-se a continuidade das instabilidades devido à necessidade de reorganização do sistema econômico-financeiro-comercial, ao novo quadro de poder global, que se interpõe como desafiador à continuidade da hegemonia dos Estados Unidos e sua moeda. 0 aprofundamento da crise na zona do Euro causa preocupação e efeitos negativos para a economia dos Estados Unidos e a global, e mesmo nos emergentes encontram-se sinais de desaceleração econômica. (PECEQUILO, 2012, p.170).
\end{abstract}

Por fim, a agenda internacional também não pode negligenciar a segurança e a defesa como essenciais aos destinos do mundo, sendo salutar aos Estados Unidos tratar destas questões com bastante critério, visto que são, desde o fim da Guerra Fria, uma liderança bélica inconteste.

É preciso pensar, na atualidade, não apenas em questões de defesa militar dos territórios físicos, como também na segurança de suas populações em sentido mais amplo e humanitário, como no combate às epidemias, das crises sociais vinculadas à miséria, e na busca por dignidade de qualidade de vida. Além disso, tratar de segurança atualmente requer avaliar "novos inimigos" como, por exemplo, os crimes cibernéticos e virtuais. (PECEQUILO, 2012, p.170).

Dentre os desafios "antigos" permanecem como prioritários os ligados à capacidade convencional de armamentos dos Estados e a proliferação de armas de destruição em massa. Esses temas e os "novos" sobrepõem-se e compõem agendas conjuntas, revelando a complexidade da pauta de segurança no século XXI. (PECEQUILO, 2012, p.171).

Como se vê, o temor pela disseminação de armas de destruição em massa, químicas, biológicas ou nucleares, é ponto certo da agenda internacional dos Estados 
Unidos na defesa e segurança globais. A abordagem fomenta embates ou tentativas de negociações para impedir a proliferação de tais armas, ainda que os Estados Unidos façam uso das suas próprias para intimidar outros países em tais negociações.

\section{Considerações finais}

Após tudo o que foi apresentado, o objetivo deste artigo foi cumprido com a delimitação da complexidade da primazia dos Estados Unidos na geopolítica internacional desde a Segunda Guerra Mundial. As ações norte-americanas ligadas à política externa comungam tendências polarizadas e ambíguas, entre posições unilateralistas e multilateralistas, segundo os objetivos de cada período histórico.

Estas práticas acabam gerando dúvidas quanto ao papel dos Estados Unidos na esfera do poder mundial, se de grande potência engajada nos assuntos de interesse internacional, como os da agenda apresentada acima, ou de nação exclusivamente autointeressada em defender e consolidar, cada vez mais, sua hegemonia. Ainda que existam modificações reais na geopolítica no mundo, com a emergência de outras potências importantes, o fato é que mediante a força ou a cooptação, os Estados Unidos vão espalhando pelo mundo seu modelo de nação.

Em um mundo permeado por novos desafios, a preservação do status quo americano está ligada à manutenção e sofisticação da produtividade da economia do país, à possibilidade de sua sociedade nacional solucionar impasses e conflitos domésticos, à conservação do destacado poderio militar, ao afastamento de tendências radicais e unilaterais que afastam, numa postura arrogante, o consenso e o diálogo estrangeiro, à crescente difusão de seu modo de vida e valores ideológicos.

Portanto, para ocuparem a dianteira global, os Estados Unidos valem-se estrategicamente de seus poderes brandos e brutos. Mas, como as relações exteriores são um campo permeado por forças em constantes disputas, resta saber como o mundo reagirá diante da possibilidade de uma liderança tão duradoura e controversa como a dos norte-americanos. 


\section{REFERÊNCIAS}

JOHNSON, Chalmers. As aflições do império. Rio de Janeiro: Record, 2007.

KIERNAN, Victor Gordon. Estados Unidos: o novo imperialismo - da colonização branca à hegemonia mundial. Rio de Janeiro: Record, 2009.

MEAD, Walter Russell. Uma orientação especial: a política externa norte-americana e sua influência no mundo. Rio de Janeiro: Biblioteca do Exército, 2006.

NYE JR., Joseph Samuel. O paradoxo do poder americano: por que a única potência do mundo não pode seguir isolada. São Paulo: Editora UNESP, 2002.

PECEQUILO, Cristina Soreanu. A política externa dos Estados Unidos: continuidade ou mudança?. Porto Alegre: Editora da UFRGS, 2005.

. Os Estados Unidos e o século XXI. Rio de Janeiro: Elsevier, 2012.

. Os Estados Unidos: hegemonia e liderança na transição. Petrópolis: Editora Vozes, 2001.

; RESENDE, Erica Simone Almeida; DINIZ, Eugenio (Orgs.). Os Estados Unidos no mundo atual. Curitiba: Juruá, 2010.

SANTOS, Marcelo. O poder norte-americano e a América Latina no pós-Guerra Fria. São Paulo: Annablume, 2007.

SANTOS, Milton. Por uma outra globalização: do pensamento único a consciência universal. Rio de Janeiro: Record, 2010.

SEVERINO, Antônio Joaquim. Metodologia do trabalho científico. São Paulo, Cortez, 2007.

TOTA, Antonio Pedro. Imperialismo sedutor: a americanização do Brasil, na época da Segunda Guerra. São Paulo, Companhia das Letras, 2000.

TODD, Emmanuel. Depois do império. Rio de Janeiro: Record, 2003. 